Research Article

\title{
Modeling of the Complex Modulus of Asphalt Mastic with Biochar Filler Based on the Homogenization and Random Aggregate Distribution Methods
}

\author{
Yushuai Wu, ${ }^{1}$ Peng Cao $\mathbb{D}^{2,3}$ Feiting Shi, ${ }^{4,5}$ Ketong Liu, ${ }^{6}$ Xuhao Wang $\left(\mathbb{D},{ }^{3,7}\right.$ Zhen Leng, \\ Zhifei Tan $\mathbb{1}^{\circ},{ }^{8}$ and Changjun Zhou ${ }^{9}$ \\ ${ }^{1}$ School of Water Resources and Electric Power, Qinghai University, Xining 810016, China \\ ${ }^{2}$ College of Architecture and Civil Engineering, Beijing University of Technology, Beijing 100124, China \\ ${ }^{3}$ Qinghai University-Tsinghua University Sanjiangyuan University Sanjiangyuan Research Institute, Qinghai University, \\ Xinning 810016, China \\ ${ }^{4}$ School of Civil Engineering, Harbin Institute of Technology, Harbin 10086, China \\ ${ }^{5}$ Civil Engineering Department, Yancheng Institute of Technology, Yancheng 224051, China \\ ${ }^{6}$ College of Architecture and Civil Engineering, Xi'an University of Science and Technology, Xi'an 710054, China \\ ${ }^{7}$ School of Highway, Chang'an University, Xi'an 710064, China \\ ${ }^{8}$ Department of Civil and Environmental Engineering, The Hong Kong Polytechnic University, Hung Hong, Kowloon, Hong Kong \\ ${ }^{9}$ School of Transportation and Logistics, Dalian University of Technology, Dalian 116024, China \\ Correspondence should be addressed to Peng Cao; caopeng518888@126.com
}

Received 5 November 2019; Revised 17 January 2020; Accepted 28 February 2020; Published 23 April 2020

Academic Editor: Candido Fabrizio Pirri

Copyright (C) 2020 Yushuai Wu et al. This is an open access article distributed under the Creative Commons Attribution License, which permits unrestricted use, distribution, and reproduction in any medium, provided the original work is properly cited.

\begin{abstract}
The disposal of agricultural straw has been a severe environmental concern in China and many other countries. In this study, the complex modulus of using biochar converted from straw as an alternative mineral filler in asphalt mastic was investigated through both laboratory tests and modeling. The experimental results indicated that the biochar can provide asphalt mastic higher stiffness than the conventional granite mineral filler. It was believed that the special porous structure of biochar providing a thicker coating layer of mineral filler increases the stiffness modulus of asphalt mastic. To consider this factor into the micromechanical model, a modified generalized self-consistent model (MGSCM) with a coating layer was proposed. Besides, the finite element (FE) microstructural model with a coating layer generated by random aggregate distribution method was used to numerically evaluate the effect of the coating layer on the complex modulus of asphalt mastics. The predicted results indicated that the generalized selfconsistent model (MGSCM) with a coating layer is an efficient and accurate model for predicting the complex modulus of asphalt mastics. Moreover, the FE modeling proved that the coating layer can significantly improve the complex modulus of asphalt mastics. Therefore, the experiments and modeling carried out in this study provided insight for biochar applications to improve the performance of asphalt mixtures.
\end{abstract}

\section{Introduction}

The disposal of tons of straw has been a serious issue in the agricultural industry in China [1]. Converting the biomass to biofuel provides an outlet for this problem. However, a large amount of biochar waste may be generated in the meantime. Thus, it becomes an increasing issue for the utilization of carbon-based waste. One efficient treatment is to use the biochar as the filler material in the asphalt paving industry. The utilization of carbonaceous materials as asphalt additives can be dated back to the 1960s [2]. By now, a great number of carbonaceous materials have been introduced, such as carbon black [2], coke dust [3], carbon fiber [4], and carbon nanotubes [5]. It has been evidenced that these carbon-based additives can positively improve the performance of asphalt mixture. Recently, with the development of 
the biofuel industry, biochar, the by-product from the biofuel manufacture process, has been used as the new carbonaceous modifier. Zhao et al. [6, 7] investigated the performances of asphalt binders and asphalt mixtures modified by biochar from switchgrass and found that biochar can improve the resistances of rutting, cracking, and moisture-induced damages. Compared to commercial carbon-based additives, the introduction of biochar seemed to perform better. Çeloğlu et al. [8] used the biochar from the walnut crust and apricot seed shell to modify the asphalt binders and found that biochar can increase the binder stiffness and thus have a potential to enhance the rutting resistance as well. Kumar et al. [9] evaluated the performance of asphalt binders with the introduction of biochar from Mesua ferrea seed cover waste and found that biochar can also decrease the aging susceptibility. They also mentioned that the irregular shape of the biochar particle may also contribute to the physicochemical interaction between biochar particle and asphalt binder. Considering these merits, it should be feasible to use it as the alternative of the conventional filler materials.

To evaluate the effects of using biochar as filler material on the asphalt pavement, characterization of the performance of biochar-modified asphalt mastic is a good way to characterize the effects of the biochar. As the asphalt mastic is the composite only of asphalt binder and filler, therefore, it makes it possible to fully evaluate the interaction between filler and asphalt binder by excluding the effects of aggregate. Besides, as asphalt mastic is the binding material and the viscoelastic component of asphalt concrete, it plays a significant role in the performance of asphalt pavement $[10,11]$. Therefore, it is critical to evaluate the viscoelastic property of asphalt mastic for the evaluation of the performance of asphalt pavement. To do that, complex modulus, composed of both dynamic modulus and the phase angle, is a commonly used parameter to depict the viscoelastic performance of asphalt materials [12]. However, although many studies have been conducted to investigate the effect of biochar on asphalt concrete, most of those investigations are based on experiments. To further explore the essence of biochar on strengthening asphalt pavement, modeling methods are highly required.

Currently, the method to predict the complex modulus of asphalt materials can be divided into numerical methods and analytical methods. The numerical methods based on finite element (FE) model and discrete element methods (DEMs) to perform simulation on the developed microstructural models. Many studies have been conducted to predict the complex modulus of asphalt materials based on the DEM and FE model [13-16]. However, one of the drawbacks of the numerical methods is the high cost for time and computation, which greatly limited their application. Different from numerical methods, the analysis is based on micromechanical models. In this method, the micromechanical models can predict the mechanical performance of heterogeneous materials based on the volumes of each composition, which provides a more efficient manner to analyze the interaction between particles and matrix. Since the 1920s, many micromechanical models, such as the dilute model (DM), the Mori-Tanaka model (MTM), the selfconsistent model (SCM), and the generalized self-consistent model (GSCM) were introduced to predict the complex modulus of asphalt materials [17-23]. However, these models only can predict the effective modulus but phase angle for viscoelastic asphalt materials [24-26]. Besides, because these models generally cannot consider the effects of physiochemical reinforcement and particle interaction, the predictions always underestimate the modulus of asphalt materials [10,26-29]. Therefore, to accurately and efficiently predict the complex modulus and time-dependent characteristic of biochar filler asphalt mastic, a more rational micromechanical model is keenly desired.

Therefore, this study aimed at predicting the viscoelastic performance of biochar-modified asphalt mastic based on computational methods. To achieve these objectives, the following research tasks have been conducted:

(i) Measuring the complex modulus of asphalt mastics through dynamic shear rheometer (DSR) tests

(ii) Developing a micromechanical model to characterize the viscoelastic performance, especially for dynamic modulus, of biochar asphalt mastic by means of homogenization method

(iii) Predicting and proving the effect of biochar on asphalt mastics based on the FE method by random aggregate generation method

\section{Experimental Program}

2.1. Material Preparation. The biochar used in this study was prepared from rice straw. The process of biochar preparation is shown in Figure 1. The dry rice straw was completely burned in an oven at $500^{\circ} \mathrm{C}$ for an hour. The residue ash was then collected and ground in a high-speed mixer for 30 seconds to obtain homogeneous biochar powder used as the mineral filler in this study.

A scanning electron microscope (SEM), FEI Quanta 250 FE-SEM, was used to examine the microstructure differences between conventional mineral filler, i.e., granite filler, and biochar filler. Figure 2 presents the SEM images of biochar and granite filler. It can be observed that the granite particles have a smooth fractured surface with an irregular shape, while the biochar particles are characterized with special porous structures with an uneven surface. Research also showed that this special structure can improve the antiaging properties of asphalt materials [30].

To prepare the asphalt mastics, asphalt binder with a penetration grade of 60/70 (Pen 60/70) was designed. The proportion of asphalt mastic was designed based on the stone mastic asphalt (SMA) due to the high asphalt binder and filler contents. In this study, SMA10, a commonly used asphalt mixture with a maximum aggregate size of $10 \mathrm{~mm}$, was selected [31]. In this mixture, the mineral filler ratio in the gradation and the binder content in the mixture are $9 \%$ and $6 \%$, respectively, which corresponds to a mass ratio of $58.5: 41.5$ of mineral filler to asphalt binder. The granite filler in the asphalt mastic was partially substituted by biochar filler with a volume fraction of $0 \%, 40 \%, 80 \%$, and $100 \%$. The 


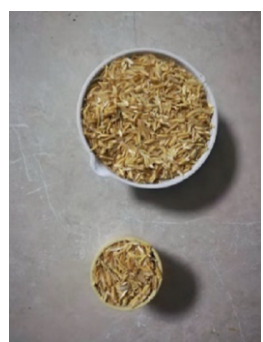

(a)

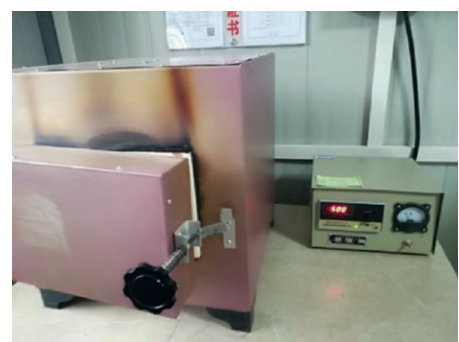

(b)

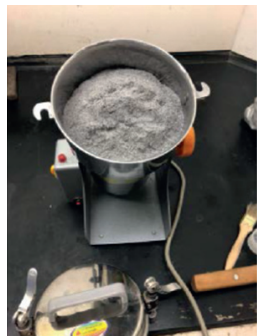

(c)

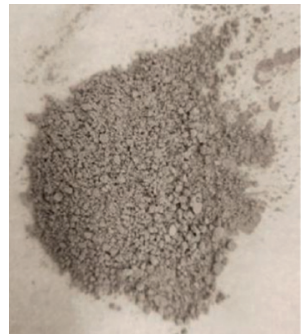

(d)

FIGURE 1: Biochar preparation progress: (a) rice straw raw material; (b) burning process; (c) grinding; (d) biochar filler.

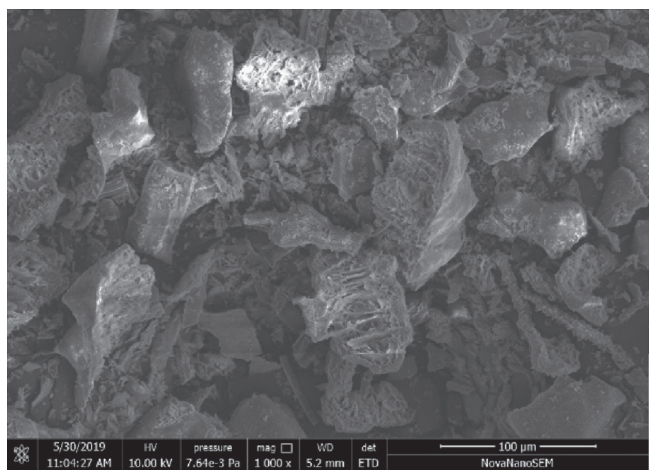

(a)

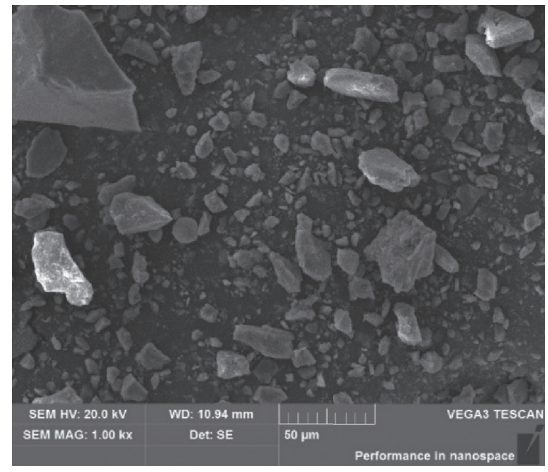

(b)

FIGURE 2: SEM images of (a) biochar and (b) granite filler.

physical properties of asphalt binder, granite filler, and biochar filler are presented in Table 1 . The mixture proportions designed in volume and mass compositions in each asphalt mastic are presented in Table 2. The biochar and granite filler materials were mixed with the hot asphalt binder at $150^{\circ} \mathrm{C}$ for 3 minutes until the mixture was prepared homogeneously.

2.2. Laboratory Tests. To characterize the viscoelastic properties of asphalt mastic, frequency sweep tests were conducted using an Anton Paar MCR 702 direct shear rheometer (DSR). The two standardized DSR configurations, i.e., $8 \mathrm{~mm}$ and $25 \mathrm{~mm}$ diameter plates for asphalt binder and asphalt mastic, with applied sinusoidal strain were used for the frequency sweep test of asphalt mastic as shown in Figure 3. Following AASHTO-T315 [32], an $8 \mathrm{~mm}$ plate was used for the test at a temperature lower than $25^{\circ} \mathrm{C}$ and a $25 \mathrm{~mm}$ plate for temperature higher than $25^{\circ} \mathrm{C}$. Tests were performed at the frequencies from $100 \mathrm{~Hz}$ to $0.1 \mathrm{~Hz}$ at the temperature from $0^{\circ} \mathrm{C}$ to $60^{\circ} \mathrm{C}$ with a $10^{\circ} \mathrm{C}$ interval. All the tests were conducted at the strain level where specimens behave linearity.

\section{Master Curve Construction}

The master curves were generated to present the complex moduli obtained from different temperatures to a given temperature based on the time-temperature superposition
TABle 1: Material properties.

\begin{tabular}{lccc}
\hline & $\begin{array}{c}\text { Asphalt } \\
\text { binder }\end{array}$ & $\begin{array}{c}\text { Granite } \\
\text { filler }\end{array}$ & $\begin{array}{c}\text { Biochar } \\
\text { filler }\end{array}$ \\
\hline $\begin{array}{l}\text { Density }\left(\mathrm{g} / \mathrm{cm}^{3}\right) \\
\begin{array}{l}\text { Elastic } \\
\text { modulus }(\mathrm{GPa})\end{array}\end{array}$ & 1.03 & 2.65 & 2.23 \\
\begin{tabular}{l} 
Poisson ratio \\
\hline
\end{tabular} & 0.49 & 60 & 60 \\
\hline
\end{tabular}

principle. The Williams-Landel-Ferry (WLF) formula was applied to shift the complex moduli to the reference temperature of $25^{\circ} \mathrm{C}$ and then the Christensen-Anderson (CA) model $[33,34]$ was further used to fit the shifted data. The WLF formula and the CA model are shown in the following equations:

$$
\log a_{T}=\frac{-C_{1}\left(T-T_{0}\right)}{C_{2}+\left(T-T_{0}\right)},
$$

where $a_{T}$ is the shift factor, $T$ is the test temperature, $T_{0}$ is the reference temperature, and $C_{1}$ and $C_{2}$ are constants.

$$
G^{*}(\omega)=G_{g}\left[1+\left(\frac{\omega_{c}}{\omega_{r}}\right)^{(\log 2) / R}\right]^{-R /(\log 2)},
$$

where $G^{*}(\omega)$ is complex shear modulus, $G_{g}$ is glass modulus assumed to be $1 \mathrm{GPa}, \omega_{r}$ is the reduced frequency at the defining temperature $(\mathrm{rad} / \mathrm{s}), \omega_{c}$ is crossover frequency at the defining temperature $(\mathrm{rad} / \mathrm{s}), \omega$ is the frequency $(\mathrm{rad} / \mathrm{s})$, and $R$ is the rheological index. 
TABLE 2: Material compositions of asphalt mastics.

\begin{tabular}{lcccccc}
\hline \multirow{2}{*}{ Asphalt mastics } & \multicolumn{3}{c}{ Mass compositions (\%) } & \multicolumn{3}{c}{ Volume compositions (\%) } \\
& Mineral filler & Biochar & Asphalt binder & Mineral filler & Biochar & Asphalt binder \\
\hline Mastic (0\%) & 58.5 & 0.0 & 41.5 & 35.4 & 0.0 & 64.6 \\
Mastic (40\%) & 36.5 & 20.4 & 43.1 & 21.2 & 14.2 & 64.6 \\
Mastic (80\%) & 12.6 & 42.5 & 44.8 & 7.1 & 28.3 & 64.6 \\
Mastic (100\%) & 0.0 & 54.2 & 45.8 & 0.0 & 35.4 & 64.6 \\
\hline
\end{tabular}

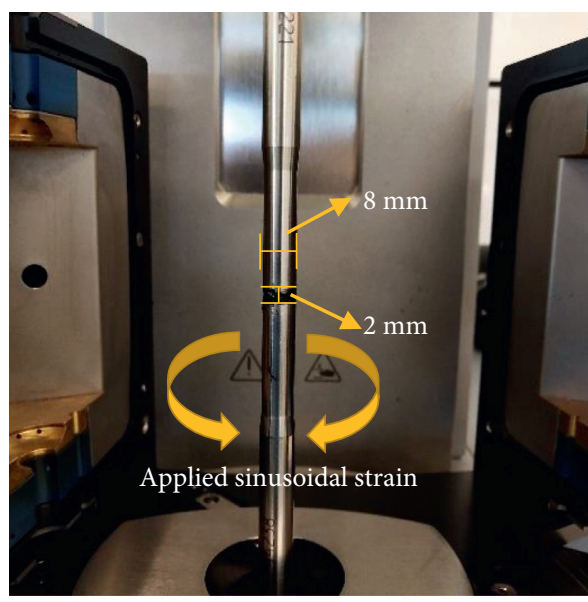

(a)

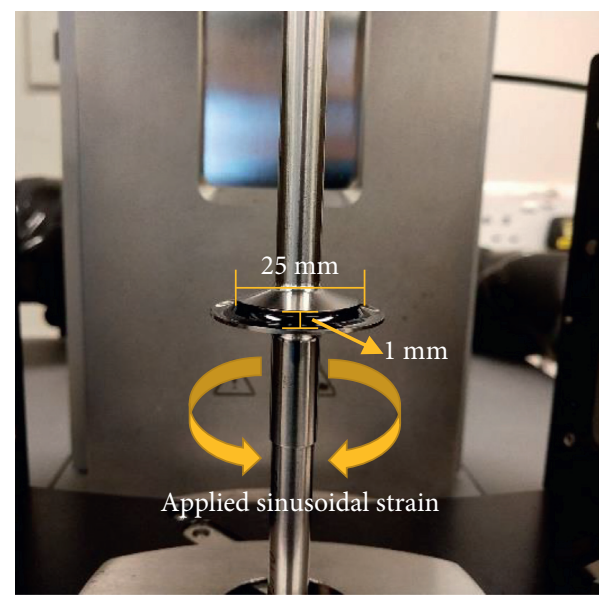

(b)

FIGURE 3: DSR measuring system used for (a) asphalt binder ( $8 \mathrm{~mm}$ plates) and (b) asphalt mastic (25 mm plates).

Table 3 presents the shift factors of WLF and parameters of the CA model of fitted master curves. Figure 4 presents a typical master curve construction of mastic $(0 \%)$. It can be observed that the CA model can fit both the dynamic modulus and phase angle curves well with high consistency.

\section{Modeling}

Figure 5 illustrates the micromechanical model used in this paper. Figure 5(a) is a commonly used GSCM. This model is composed of three layers including the asphalt binder, aggregate, and a homogenized material layer [10]. One of the drawbacks of this model is that it cannot take the coating layer on the surface of the filler particle into the model. However, this coating layer can significantly affect the mechanical performance of asphalt mastic [30]. Therefore, this model generally underestimates the modulus of asphalt mixes. To solve this problem, a four-phase micromechanical model including the coating layer was therefore proposed to predict the complex modulus of asphalt mastic named modified generalized self-consistent model (MGSCM). This micromechanical model was proposed by Doghri $[35,36]$, which is composed of four different phases including effective homogeneity matrix, real matrix, coating layer, and inclusion compared with the traditional GSCM model as illustrated in Figure 5. Peng et al. [23] have developed this method for investigating the upper limit and lower limit of dynamic modulus of the asphalt concrete.
In this MGSCM model, the inclusions, mineral filler, and biochar filler were assumed as elastic components with an elastic modulus and Poisson's ratio of $60 \mathrm{GPa}$ and 0.15 , respectively. To describe the viscoelastic properties of asphalt binder, the complex modulus master curves of asphalt binder were expressed as the Prony series model as presented in Table 4. The Prony series parameters were determined by minimizing the storage modulus and loss modulus [37]. Figure 6 displays the master curves of asphalt binder expressed by the CA model and Prony series model. It is worth noting that the Prony series model can fit the CA model master curve with high accuracy within a wide frequency range from $10^{-4} \mathrm{~Hz}$ to $10^{4} \mathrm{~Hz}$. The process to determine the coating layer's properties may follow the flowchart presented in Figure 7 due to the complexity of physical measurement on the coating layer. The coating layer was assumed as an elastic component due to the relatively high stiffness modulus compared with asphalt binder. A Poisson's ratio of 0.15 was assumed because of its marginal effect on complex modulus perdition. The thickness of the coating layer was then determined when the complex modulus at low frequency reached the minimum relative error while this thickness was then used to determine the elastic modulus of the coating layer when the complex modulus at high frequency reached the minimum relative error. The complex modulus master curves of the asphalt mastic (0\%) and asphalt mastic (100\%) were predicted. Both models including GSCM and MGSCM were used to predict 
TABLe 3: Parameters of the WLF formula and CA model for asphalt binder and mastics.

\begin{tabular}{lccccccc}
\hline & Parameters & Unit & Asphalt binder & Mastic (0\%) & Mastic (40\%) & Mastic (80\%) & Mastic (100\%) \\
\hline \multirow{2}{*}{ WLF formula } & $C_{1}$ & - & 13.56 & 15.144 & 15.70 & 15.23 & 16.27 \\
& $C_{2}$ & - & 132.24 & 144.334 & 148.91 & 149.26 & 1.27 .23 \\
\multirow{4}{*}{ CA model } & $R$ & - & 1.18 & 1.116 & 1.16 & 1.04 & $1.00 E+09$ \\
& $G_{g}$ & $\mathrm{~Pa}$ & $3.50 E+08$ & $5.20 E+08$ & $1.20 E+09$ & $1.20 E+09$ \\
$R^{2}$ & $\omega_{c}$ & $\mathrm{rad} / \mathrm{s}$ & 977 & 985 & $7.42 E+02$ & $6.28 E+02$ & $5.38 E+02$ \\
& $\left|G^{*}\right|$ & - & 0.999 & 0.999 & 0.999 & 0.999 & 0.998 \\
& $\theta$ & - & 0.995 & 0.998 & 0.998 & 0.998 & 0.997 \\
\hline
\end{tabular}

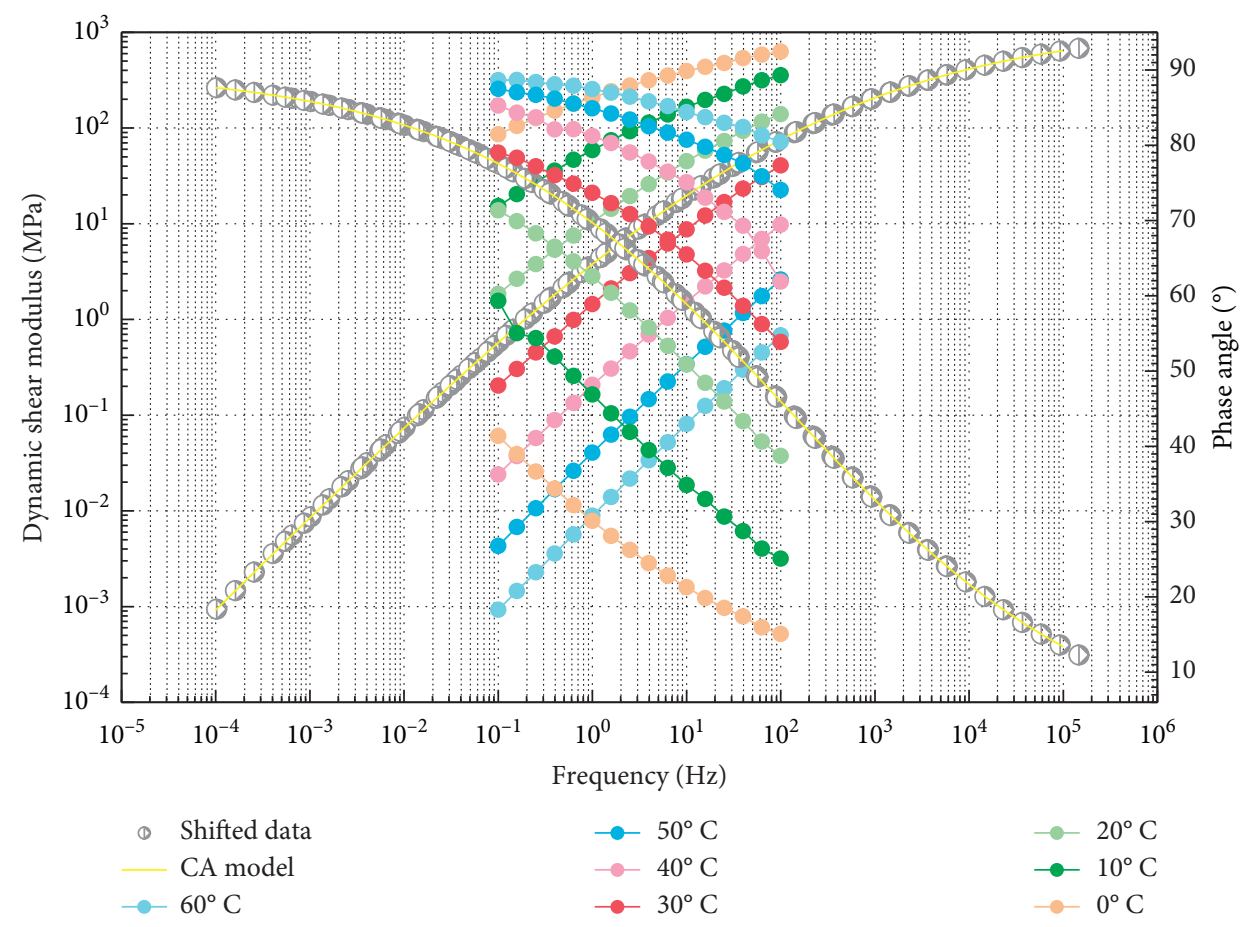

Figure 4: Master curve construction of mastic (0\%).

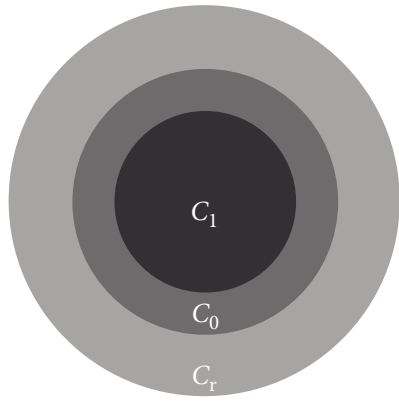

Homogenized material: $C_{\mathrm{r}}$ Asphalt binder: $C_{0}$ Aggregate: $C_{1}$

(a)

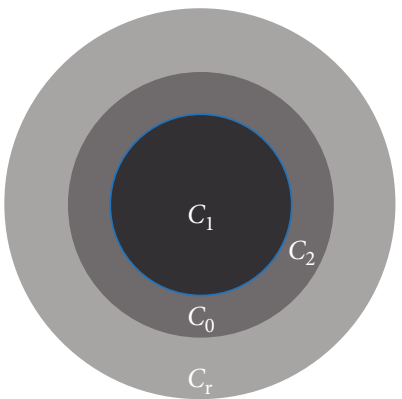

Homogenized material: $C_{\mathrm{r}}$ Asphalt binder: $C_{0}$

Aggregate: $C_{1}$ Coating layer: $C_{2}$

(b)

Figure 5: Schematic diagrams of micromechanical models: (a) GSCM and (b) MGSCM. 
TABle 4: Prony series model parameters of asphalt binder at $25^{\circ} \mathrm{C}$.

\begin{tabular}{lcc}
\hline & \multicolumn{2}{c}{ Pen60/70 } \\
Series no. $G_{0=} 206.241 \mathrm{MPa}$ \\
& $\tau_{i}(\mathrm{~s})$ & $\alpha_{i}(-)$ \\
\hline 1 & $4.955 E-06$ & $5.347 E-01$ \\
2 & $1.851 E-05$ & $2.601 E-02$ \\
3 & $6.916 E-05$ & $2.420 E-01$ \\
4 & $2.584 E-04$ & $8.287 E-02$ \\
5 & $9.652 E-04$ & $7.005 E-02$ \\
6 & $3.606 E-03$ & $2.733 E-02$ \\
7 & $1.347 E-02$ & $1.190 E-02$ \\
8 & $5.033 E-02$ & $3.671 E-03$ \\
9 & $1.880 E-01$ & $1.113 E-03$ \\
10 & $7.024 E-01$ & $2.705 E-04$ \\
11 & $2.624 E+00$ & $6.830 E-05$ \\
12 & $9.804 E+00$ & $1.300 E-05$ \\
13 & $3.663 E+01$ & $3.720 E-06$ \\
14 & $1.368 E+02$ & $3.383 E-07$ \\
15 & $5.112 E+02$ & $2.492 E-07$ \\
\hline
\end{tabular}

the complex modulus of asphalt mastics. The MSC Digimat software system was used to conduct the modeling. The simulation process can be completed in seconds to obtain the complex moduli within the whole frequency range from $10^{-4} \mathrm{~Hz}$ to $10^{4} \mathrm{~Hz}$.

\section{Results and Discussion}

5.1. Complex Moduli. Figure 8 presents the complex modulus curves representing both dynamic modulus and phase angle of asphalt mastics with different biochar volume fractions. It can be observed that with the increasing volume substitution of biochar filler, the dynamic moduli of mastics increase but the phase angle decreases regarding frequency. This means that the biochar can stiffen the asphalt mastics. It is expected that the porous structure of biochar enhances the absorption of asphalt binder and then further increases the stiffness of asphalt mastics. To quantify the effect of biochar on the dynamic moduli and phase angles, their relative errors at low, high, and the whole frequency ranges are listed in Table 5. It is worth noting that a significant increase in dynamic modulus can be observed with the biochar substitutions from $0 \%$ to $100 \%$ and a $50 \%$ modulus increase can be achieved with a $100 \%$ biochar substitution. Besides, compared the differences in different frequency ranges, it can be found that the increase of dynamic modulus is substantially higher than the dynamic modulus at low frequency, and with the increase of substitution, this tendency becomes more noticeable, which means that the stiffening effect of biochar is strengthened with the biochar increase. Based on the performance of biochar mastic, it can be concluded that biochar filler can exhibit low deformation at long-term loading and high temperature, which indicates a better rutting resistance of asphalt pavement constructed by biochar filler than the conventional mineral filler.

5.2. Modeling. The complex moduli of asphalt mastic (0\%) and mastic (100\%) were predicted by both GSCM and
MGSCM models. The experimental and the predicted master curves for both mastics are displayed in Figures 9 and 10 , and the corresponding errors are presented in Table 6. It can be seen that both models can well capture the trend of complex modulus for both mastics as indicated by high $R^{2}$ values of around 1. However, the GSCM substantially underestimates the dynamic modulus for both granite and biochar filler asphalt mastics with relative errors of $32 \%$ and $56 \%$ for mastic $(0 \%)$ and mastic $(100 \%)$, respectively. It is believed that the existence of the coating layer in the real mastic increases the experimental modulus of mastics. As mentioned before, due to the physiochemical reinforcement between filler particles and asphalt binder, the modulus of the coating layer will increase significantly and then further increase the overall modulus of asphalt mastic. However, this factor cannot be considered in the GSCM model. Therefore, to give a correct prediction, it is required to take the coating layer into the micromechanical model. To this end, the coating layer was introduced into the MGSCM model. From Figures 9 and 10, we can find that, with the introduction of the coating layer, significant improvement is achieved for the predicted master curves for both mastics and only the relative errors for both dynamic modulus and phase angle predictions on both mastics are narrowed down to less than $5 \%$. Therefore, the results demonstrate that the MGSCM considering the coating layer can give an accurate prediction for the viscoelastic performance of asphalt mastics.

The properties of the coating layer are presented in Table 7. In the model, a thicker and high modulus coating layer was applied to mastic (100\%) with biochar filler than the conventional filler mastic (0\%) with granite filler. This is also consistent with the SEM test result, which indicates the biochar particles are characterized with special porous structures with an uneven surface. This porous structure indicates the biochar filler can have a thicker coating layer than the conventional granite filler with a smooth surface.

\subsection{Dynamic Modulus Simulation based on the FE Method.} The viscoelastic property of asphalt materials is derived from that of asphalt binder. The complex modulus of the composites can be directly obtained from laboratory tests [25]. Besides, from the continuum mechanics aspect, asphalt mixtures were regarded as a representative volume element (RVE) composed of asphalt binder, aggregate particles, and air voids. Thus, the complex modulus is transferred to a calculable parameter of the resultant function of their mechanical properties, volume contents, and space location [19].

As the aggregate particle is an elastic material, the viscoelastic property of asphalt mastic is determined by asphalt matrix. For FE simulation, the linear transformation is required for the viscoelastic matrix [26]. Prony series model was adopted for linear transformation. The deviation is as follows: firstly, the sinusoidal external strain load is expressed as

$$
\varepsilon(t)=\varepsilon_{0} \exp (i \omega t)
$$

By replacing $\varepsilon(t)$ with progressive relaxation modulus, the following stress expression can be obtained: 


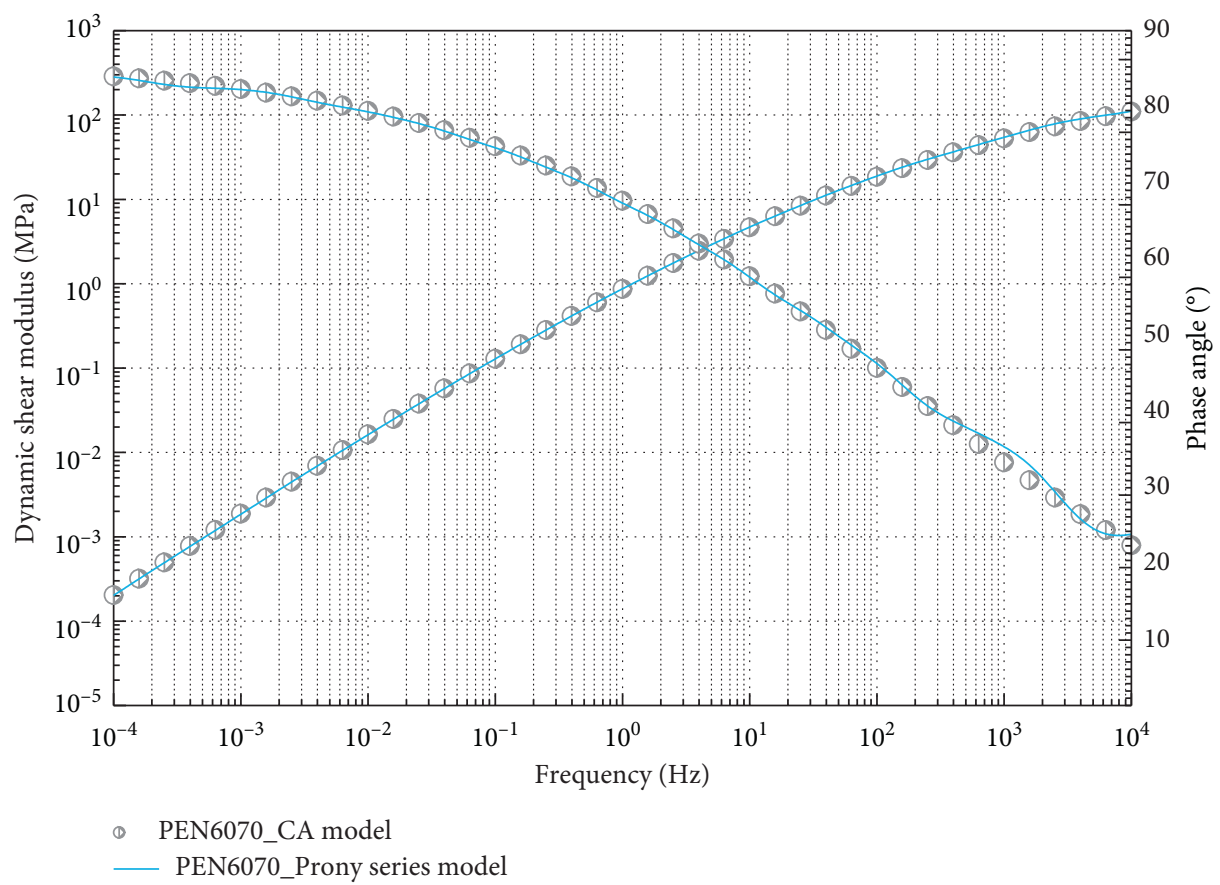

Figure 6: Dynamic shear modulus and phase angle master curves fitted by the CA model and the corresponding Prony series for Pen6070 at $25^{\circ} \mathrm{C}$.

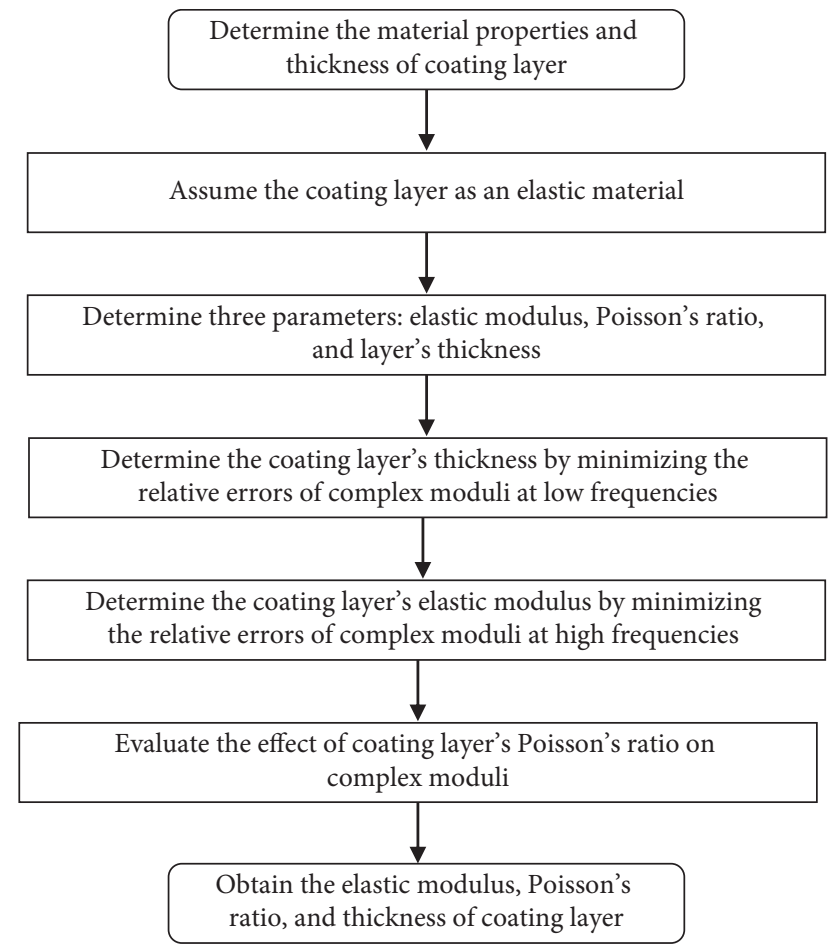

FIGURE 7: Flowchart of coating layer characterization procedures.

$$
\begin{aligned}
\sigma(t) & =E_{\infty} \varepsilon(t)-\int_{0}^{\infty} e(\tau) \frac{\mathrm{d}}{\mathrm{d} \tau}\left(E_{\infty} \varepsilon_{0} \exp (i \omega(t-\tau))\right) \mathrm{d} \tau \\
& =E_{\infty}\left(1+i \omega \int_{0}^{\infty} e(\tau) \exp (-i \omega \tau) \mathrm{d} \tau\right) \mathcal{\varepsilon}(t)
\end{aligned}
$$

where $e(t)=\left(E(t) / E_{\infty}\right)-1$ is the relaxation formula after regulation and $\tau$ is the relaxation time.
Based on equation (4), the relationship of stress and strain can be redefined as follows:

$$
\sigma(t)=E^{*}(\omega) \mathcal{\varepsilon}(t) .
$$

Comparing equation (4) with equation (5), the expression of complex modulus can be written as $E^{*}(\omega)=E_{\infty}(1+i \omega \mathrm{e}(\omega))$, where $\mathrm{e}(\omega)$ is the transformed term of $e(t)$ after Fourier transform. e $(\omega)$ can be expressed as $\mathrm{e}(\omega)=\operatorname{Re}(e(\omega))+i \operatorname{Im}(\mathrm{e}(\omega))$. Therefore, the complex modulus can be further expressed as follows:

$$
E^{*}(\omega)=\underbrace{E_{\infty}(1-\omega \operatorname{Im}(e(\omega)))}_{E_{s}(\omega)}+i \underbrace{E_{\infty} \omega \operatorname{Re}(e(\omega))}_{E_{l}(\omega)},
$$

where $E_{s}(\omega)$ is storage modulus and $E_{l}(\omega)$ is loss modulus.

By rewriting equation (6), the following equation is obtained:

$$
\left.\begin{array}{l}
\operatorname{Im}(\omega e(\omega))=1-\frac{E_{s}(\omega)}{E_{\infty}} \\
\operatorname{Re}(\omega e(\omega))=\frac{E_{l}(\omega)}{E_{\infty}}
\end{array}\right\} .
$$

Therefore, the complex modulus is expressed as the progressive relaxation moduli at different frequencies, which can be used as a viscoelastic constitutive model in the FE simulation [38].

5.4. FE Results. To prove the assumption of the coating layer in the MGSCM, FE simulation was also conducted. The simulations based on mastic (0\%) and mastic (100\%) were performed. In the FE simulation, the complex moduli of asphalt mastic within the frequency range from $10^{-2} \mathrm{~Hz}$ to 


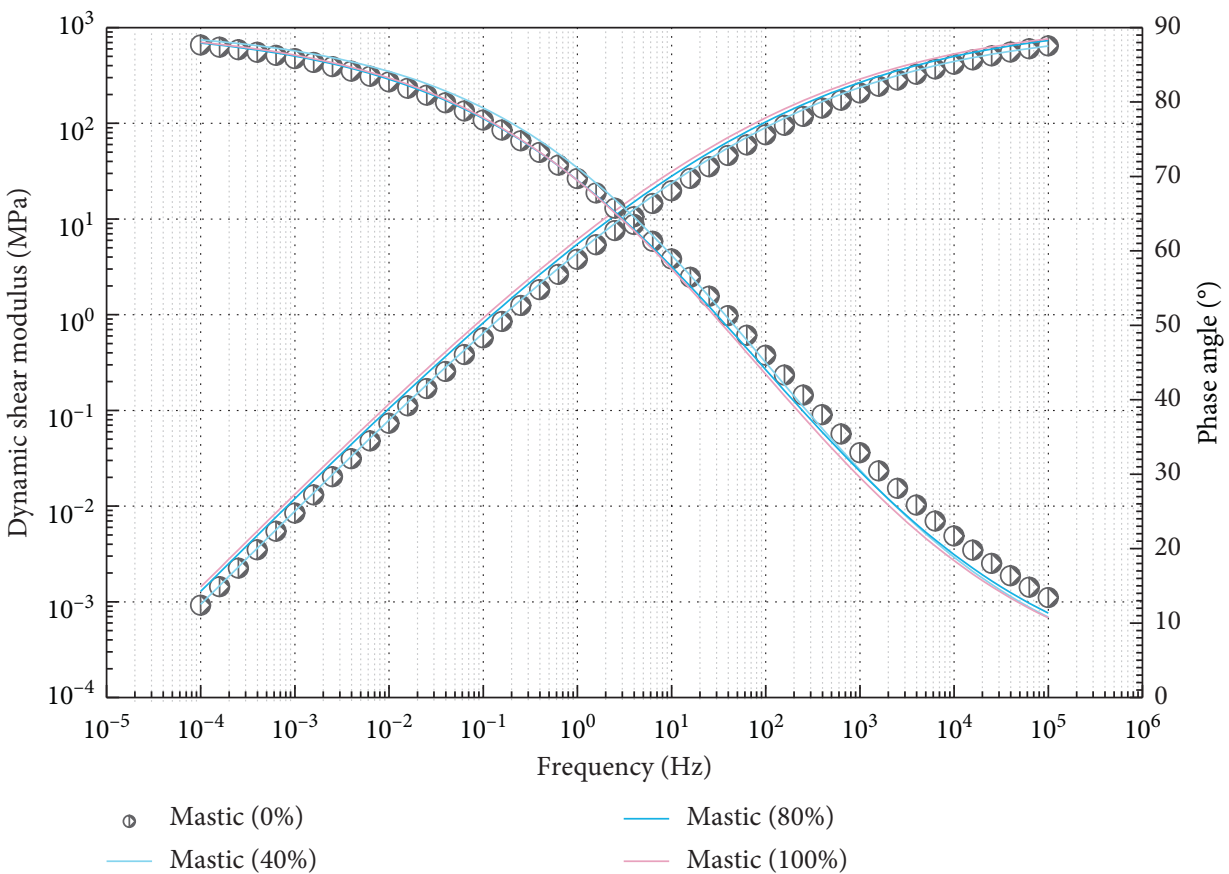

Figure 8: Complex modulus master curves of asphalt mastic.

TABLE 5: Relative differences in complex modulus (\%).

\begin{tabular}{lcccc}
\hline Frequency range & Complex modulus & Mastic (40\%) & Mastic (80\%) & Mastic (100\%) \\
\hline \multirow{2}{*}{ Low frequencies $\left(10^{-4} \mathrm{~Hz} \sim 10^{-3} \mathrm{~Hz}\right)$} & Dynamic modulus & 10.99 & 41.00 & 56.53 \\
& Phase angle & 1.01 & 0.37 & 0.51 \\
High frequencies $\left(10^{3} \mathrm{~Hz} \sim 10^{4} \mathrm{~Hz}\right)$ & Dynamic modulus & 3.50 & 25.02 & 33.98 \\
Whole frequencies $\left(10^{-4} \mathrm{~Hz} \sim 10^{4} \mathrm{~Hz}\right)$ & Phase angle & 10.00 & 12.60 & 53.92 \\
& Dynamic modulus & 12.75 & 38.93 & 2.61 \\
\hline
\end{tabular}

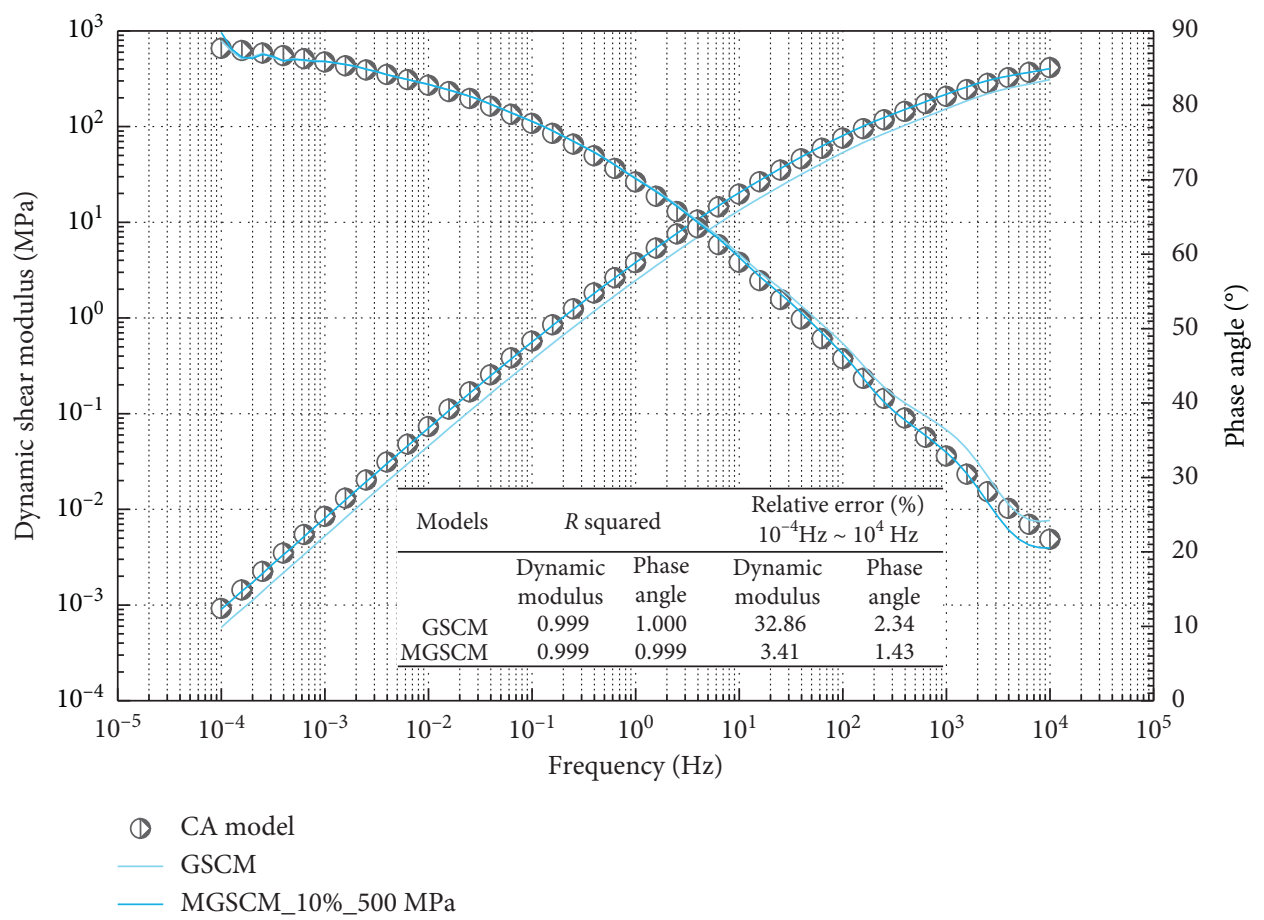

Figure 9: Predicted complex moduli for mastic (0\%). 


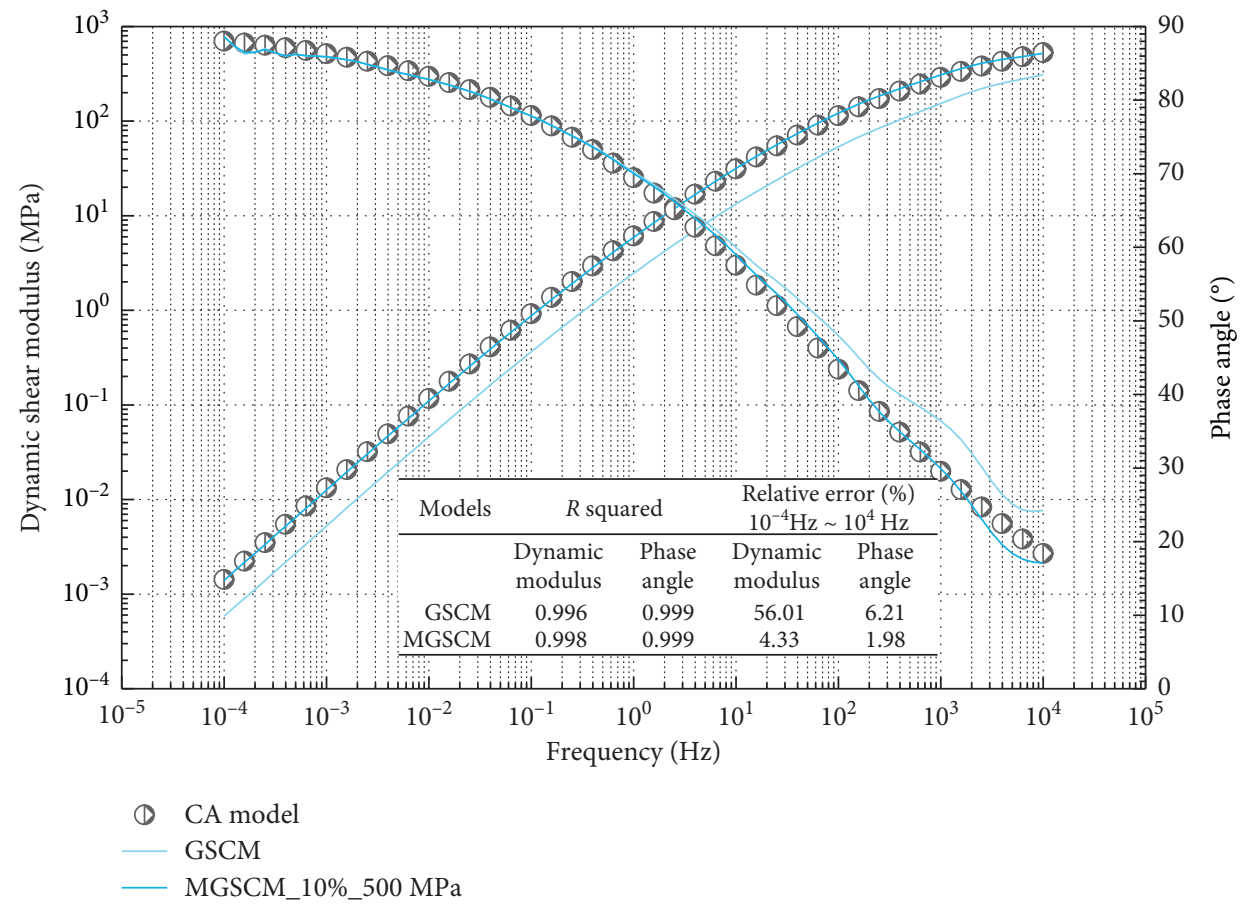

FIgURE 10: Predicted complex moduli for mastic (100\%).

TABLE 6: Error analysis for complex moduli of asphalt mastics.

\begin{tabular}{|c|c|c|c|c|c|}
\hline \multirow[t]{2}{*}{ Mastic } & \multirow[t]{2}{*}{ Models } & \multicolumn{2}{|c|}{$R$ squared } & \multicolumn{2}{|c|}{$\begin{array}{c}\text { Relative error (\%) } \\
\left(10^{-4} \mathrm{~Hz} \sim 10^{4} \mathrm{~Hz}\right)\end{array}$} \\
\hline & & Dynamic modulus & Phase angle & Dynamic modulus & Phase angle \\
\hline \multirow{2}{*}{ Mastic (0\%) } & GSCM & 0.999 & 1.000 & 32.9 & 2.3 \\
\hline & MGSCM & 0.999 & 0.999 & 3.4 & 1.4 \\
\hline \multirow{2}{*}{ Mastic (100\%) } & GSCM & 0.996 & 0.999 & 56.0 & 6.2 \\
\hline & MGSCM & 0.998 & 0.999 & 4.3 & 2.0 \\
\hline
\end{tabular}

TABLE 7: Coating layer properties.

\begin{tabular}{lccc}
\hline & Coating layer relative thickness (\%) & Elastic modulus (MPa) & Poisson's ratio \\
\hline Mastic $(0 \%)$ & 10 & 500 & 0.15 \\
Mastic $(100 \%)$ & 17 & 800 & 0.15 \\
\hline
\end{tabular}

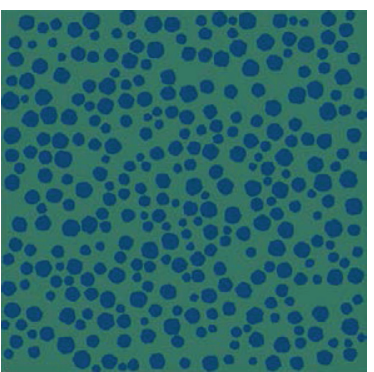

(a)

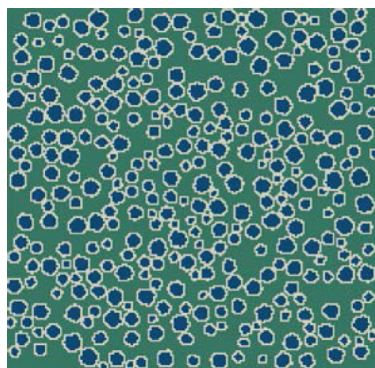

(b)

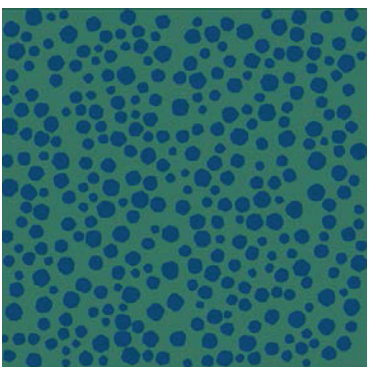

(c)

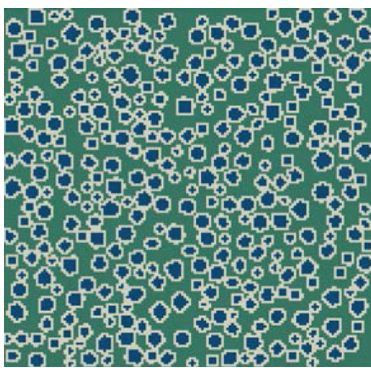

(d)

FIgURE 11: Microstructural models in the FE simulations. The microstructural model (a) without a coating layer for mastic (0\%), (b) with a coating layer for mastic (0\%), (c) without a coating layer for mastic (100\%), and (d) with a coating layer for mastic (100\%). 


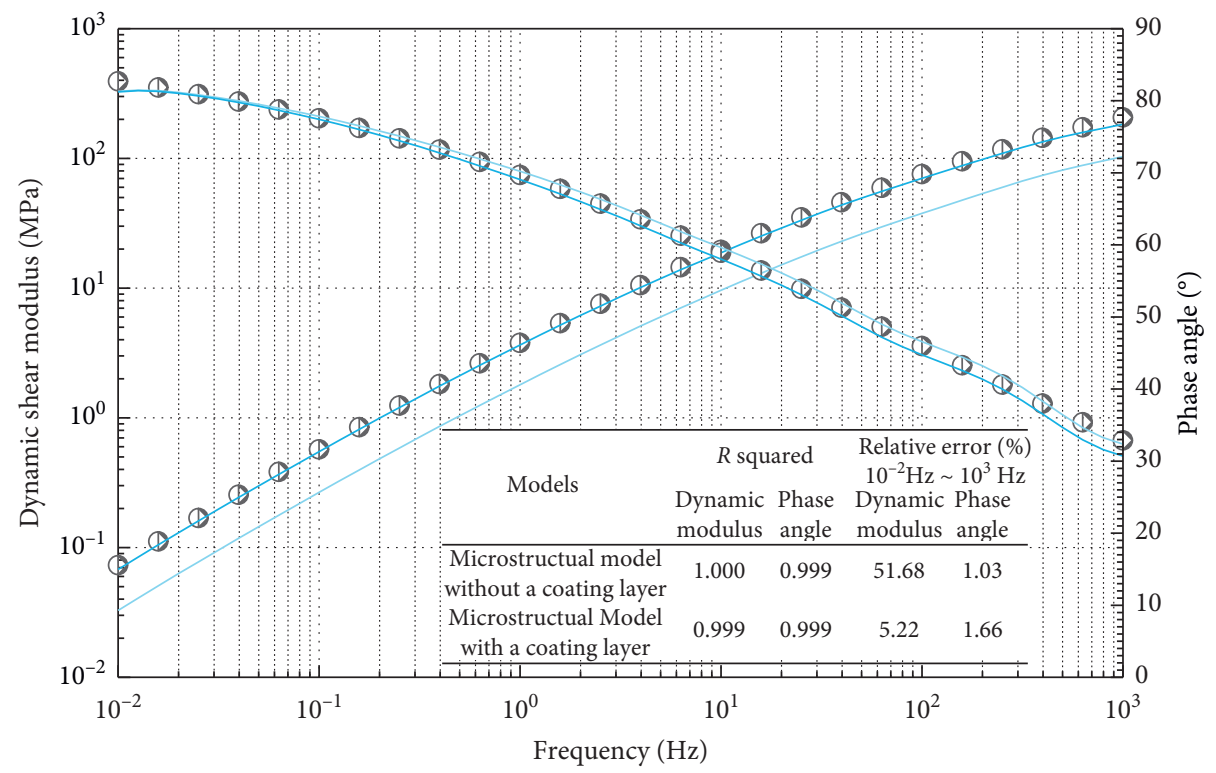

- Experimental curve

_ FE_microstructure without a coating layer

_ FE_microstructure with a coating layer

(a)

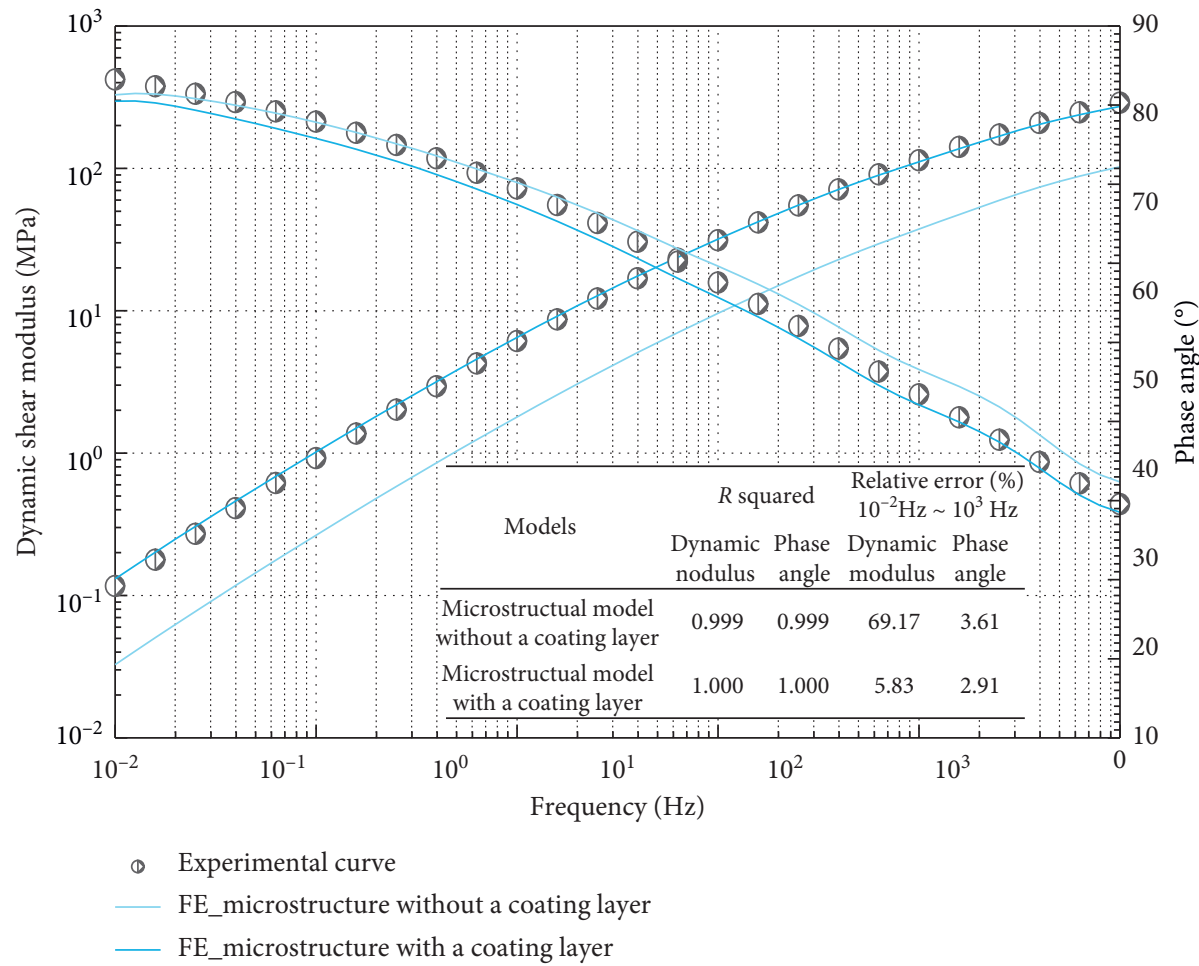

(b)

Figure 12: Predicted complex modulus master curves based on FE simulation. (a) Mastic (0\%) and (b) mastic (100\%).

$10^{3} \mathrm{~Hz}$ were predicted based on the steady-state dynamic (SSD) method, which is an efficient and accurate method to predict the complex modulus of asphalt materials $[39,40]$. To consider the coating layer effect, the microstructural models with a coating layer and without a coating layer were developed based on a random aggregate distribution algorithm. The developed models for the two mastics were presented in Figure 11. The coating layer thicknesses of $1 \mu \mathrm{m}$ and $1.35 \mu \mathrm{m}$ were assigned to the mastic $(0 \%)$ and mastic $(100 \%)$, respectively. The corresponding predicted complex 
modulus master curves are presented in Figure 12. It can be observed that the FE simulation based on the microstructural model without a coating layer underestimates the dynamic shear moduli within the whole frequency range for both mastics, but significant improvement was achieved for both mastics after a thin coating layer was added. This result verifies the existence of the coating layer. Besides, since the coating layer of mastic $(100 \%)$ is thicker than that of mastic $(0 \%)$, it also proves the assumption that the biochar filler particle is attributed to a thicker coating layer than the granite filler particle in the MGSCM.

\section{Summary and Conclusions}

In this study, biochar converted from straw was used as an alternative mineral filler in asphalt mastic. The complex moduli of mastics with different biochar contents were measured by laboratory tests firstly. Then, the complex moduli were predicted by the proposed micromechanical model based on homogeneous theory. Further, the complex moduli of asphalt mastics were predicted and analyzed by FE simulations based on microstructure models. Based on the outcome of this study, the following conclusions can be drawn:

(i) The modified MGSCM by considering the coating layer can effectively predict the complex modulus of biochar-modified asphalt mastic

(ii)The predictions based on FE simulation by random aggregate generation method have a good correlation with the predictions based on MGSCM and experimental results, which verifies the accuracy of MGSCM in the complex modulus prediction of asphalt mastic, and this method can be further extended to other areas

(iii)Biochar filler can improve the modulus of mastic by developing a thick coating layer to improve the modulus of mastics, which would contribute to the rutting performance of asphalt pavement

\section{Data Availability}

All the data used to support the findings of this study are included within the article.

\section{Conflicts of Interest}

The authors declare that they have no conflicts of interest.

\section{Acknowledgments}

This work was financially supported by the National Natural Science Foundation of China (Grant nos. 51769028, 51861165102, and 51508137), the Natural Science Foundation of Qinghai Province in China (Grant nos. 2017-ZJ933Q, 2017-QGY-7, and 2018-0301-ZJC-0254), Science and Technology Projects of Ministry of Housing and UrbanRural Development of China (Grant no. 2018-K9-054), and National Key Laboratory Project for Water Sand Science and
Water and Hydropower Engineering, Tsinghua University (Grant no. sklhse-2018-B-03).

\section{References}

[1] X. Zeng, Y. Ma, and L. Ma, "Utilization of straw in biomass energy in China," Renewable and Sustainable Energy Reviews, vol. 11, no. 5, pp. 976-987, 2007.

[2] A. Aliotti, "Carbon black-its nature and possible effects on the characteristics of bituminous road binders," in Proceedings of the Australian Road Research Board (ARRB) Conference, vol. 1, no. 2, pp. 912-917, Canberra, Australia, January 1962.

[3] R. Taha, G. Ali, and M. Delwar, "Evaluation of coke dustmodified asphalt using superpave," Journal of Materials in Civil Engineering, vol. 10, no. 3, pp. 174-179, 1998.

[4] B. Huang, X. Chen, and X. Shu, "Effects of electrically conductive additives on laboratory-measured properties of asphalt mixtures," Journal of Materials in Civil Engineering, vol. 21, no. 10, pp. 612-617, 2009.

[5] H. Ziari, H. Farahani, A. Goli, and S. S. Galooyak, "The investigation of the impact of carbon nano tube on bitumen and HMA performance," Petroleum Science and Technology, vol. 32, no. 17, pp. 2102-2108, 2014.

[6] S. Zhao, B. Huang, X. P. Ye, X. Shu, and X. Jia, "Utilizing biochar as a bio-modifier for asphalt cement: a sustainable application of bio-fuel by-product," Fuel, vol. 133, pp. 52-62, 2014.

[7] S. Zhao, B. Huang, X. Shu, and P. Ye, "Laboratory investigation of biochar-modified asphalt mixture," Transportation Research Record: Journal of the Transportation Research Board, vol. 2445, no. 1, pp. 56-63, 2014.

[8] M. E. Çeloğlu, Y. Mehmet, B. V. Kök, and E. Yalçin, "Effects of various biochars on the high temperature performance of bituminous binder," in Proceedings of the 6th Euraphalt \& Eurobitume Congress, Prague, Czech Republic, June 2016.

[9] A. Kumar, R. Choudhary, R. Narzari, R. Kataki, and S. K. Shukla, "Evaluation of bio-asphalt binders modified with biochar: a pyrolysis by-product of Mesua ferrea seed cover waste," Cogent Engineering, vol. 5, no. 1, pp. 1-15, 2018.

[10] H. M. Yin, W. G. Buttlar, G. H. Paulino, and H. D. Benedetto, "Assessment of existing micro-mechanical models for asphalt mastics considering viscoelastic effects," Road Materials and Pavement Design, vol. 9, no. 1, pp. 31-57, 2008.

[11] P. Chaturabong and H. U. Bahia, "Effect of moisture on the cohesion of asphalt mastics and bonding with surface of aggregates," Road Materials and Pavement Design, vol. 19, no. 3, pp. 741-753, 2018.

[12] R. Nemati and E. V. Dave, "Nominal property based predictive models for asphalt mixture complex modulus (dynamic modulus and phase angle)," Construction and Building Materials, vol. 158, pp. 308-319, 2018.

[13] P. Cao, D. Feng, and C. Zhou, "A modified damage-plasticity coupled area-weighted nonlocal model for simulating ductile fracture and softening behaviors of materials," Mathematical Problems in Engineering, vol. 2014, Article ID 862543, 10 pages, 2014.

[14] P. Cao, D. Feng, C. Zhou, and W. Zuo, "Study on fracture behavior of polypropylene fiber reinforced concrete with bending beam test and digital speckle method," Computers and Concrete, vol. 14, no. 5, pp. 527-546, 2014.

[15] K. Z. Rami, S. Amelian, Y.-R. Kim, T. You, and D. N. Little, "Modeling the 3D fracture-associated behavior of viscoelastic asphalt mixtures using 2D microstructures," Engineering Fracture Mechanics, vol. 182, pp. 86-99, 2017. 
[16] Q. Dai and Z. You, "Prediction of creep stiffness of asphalt mixture with micromechanical finite-element and discreteelement models," Journal of Engineering Mechanics, vol. 133, no. 2, pp. 163-173, 2007.

[17] W. Ogierman and G. Kokot, "Mean field homogenization in multi-scale modelling of composite materials," Journal of Achievements in Materials and Manufacturing Engineering, vol. 61, no. 2, pp. 343-348, 2013.

[18] W. G. Buttlar and R. Roque, "Evaluation of empirical and theoretical models to determine asphalt mixture stiffnesses at low temperatures (with discussion)," Journal of the Association of Asphalt Paving Technologists, vol. 65, pp. 99-141, 1996.

[19] W. G. Buttlar, D. Bozkurt, G. G. Al-Khateeb, and A. S. Waldhoff, "Understanding asphalt mastic behavior through micromechanics," Transportation Research Record: Journal of the Transportation Research Board, vol. 1681, no. 1, pp. 157-169, 1999.

[20] N. Shashidhar and A. Shenoy, "On using micromechanical models to describe dynamic mechanical behavior of asphalt mastics," Mechanics of Materials, vol. 34, no. 10, pp. 657-669, 2002.

[21] Y.-R. Kim and D. N. Little, "Linear viscoelastic analysis of asphalt mastics," Journal of Materials in Civil Engineering, vol. 16, no. 2, pp. 122-132, 2004.

[22] C. Zhou, D. Feng, X. Wu, P. Cao, and X. Fan, "Prediction of concrete coefficient of thermal expansion by effective selfconsistent method considering coarse aggregate shape," Journal of Materials in Civil Engineering, vol. 30, no. 12, Article ID 04018312, 2018.

[23] C. Peng, J. Feng, S. Feiting, Z. Changjun, and F. Decheng, "Modified two-phase micromechanical model and generalized self-consistent model for predicting dynamic modulus of asphalt concrete," Construction and Building Materials, vol. 201, pp. 33-41, 2019.

[24] B. Huang, X. Shu, G. Li, and L. Chen, "Analytical modeling of three-layered HMA mixtures," International Journal of Geomechanics, vol. 7, no. 2, pp. 140-148, 2007.

[25] X.-y. Zhu, X. Wang, and Y. Yu, "Micromechanical creep models for asphalt-based multi-phase particle-reinforced composites with viscoelastic imperfect interface," International Journal of Engineering Science, vol. 76, pp. 34-46, 2014.

[26] J. Zhang, Z. Fan, J. Pei, R. Li, and M. Chang, "Multiscale validation of the applicability of micromechanical models for asphalt mixture," Advances in Materials Science and Engineering, vol. 2015, Article ID 937126, 8 pages, 2015.

[27] F. F. Tehrani, J. Absi, F. Allou, and C. Petit, "Viscoelastic properties of bituminous composites using multiscale heterogeneous numerical simulation and micromechanical analytical self-consistent model," in Proceedings of the 8th RILEM International Conference on Mechanisms of Cracking and Debonding in Pavements, vol. 13, Springer, Egletons, France, pp. 133-138, January 2016.

[28] H. Zhang, K. Anupam, A. Scarpas, and C. Kasbergen, "Comparison of different micromechanical models for predicting the effective properties of open graded mixes," Transportation Research Record: Journal of the Transportation Research Board, vol. 2672, no. 28, pp. 404-415, 2018.

[29] Y. Zhang, T. Ma, M. Ling, D. Zhang, and X. Huang, "Predicting dynamic shear modulus of Asphalt mastics using discretized-element simulation and reinforcement mechanisms," Journal of Materials in Civil Engineering, vol. 31, no. 8, Article ID 04019163, 2019.
[30] B. S. Underwood and Y. R. Kim, "A four phase micro-mechanical model for asphalt mastic modulus," Mechanics of Materials, vol. 75, pp. 13-33, 2014.

[31] H. Yu, Z. Leng, Z. Dong, Z. Tan, F. Guo, and J. Yan, "Workability and mechanical property characterization of asphalt rubber mixtures modified with various warm mix asphalt additives," Construction and Building Materials, vol. 175, pp. 392-401, 2018.

[32] AASHTO-T315, Standard Method of Test for Determining the Rheological Properties of Asphalt Binder Using a Dynamic Shear Rheometer (DSR), American Association of State Highways and Transportation Officials (AASHTO), Washington, DC, USA, 2019.

[33] D. A. Anderson, D. W. Christensen, and H. Bahia, "Physical properties of asphalt cement and the development of performance-related specifications," Journal of the Association of Asphalt Paving Technologists, vol. 60, pp. 437-475, 1991.

[34] D. W. Christensen and D. A. Anderson, "Interpretation of dynamic mechanical test data for paving grade asphalt cements (with discussion)," Journal of the Association of Asphalt Paving Technologists, vol. 61, pp. 67-116, 1992.

[35] I. Doghri and C. Friebel, "Effective elasto-plastic properties of inclusion-reinforced composites. Study of shape, orientation and cyclic response," Mechanics of Materials, vol. 37, no. 1, pp. 45-68, 2005.

[36] O. Pierard, C. González, J. Segurado, J. Lorca, and I. Doghri, "Micromechanics of elasto-plastic materials reinforced with ellipsoidal inclusions," International Journal of Solids and Structures, vol. 44, no. 21, pp. 6945-6962, 2007.

[37] M. F. Woldekidan, Response Modelling of Bitumen, Bituminous Mastic and Mortar, Allen Institute for AI, Washington, DC, USA, 2011.

[38] B. S. Underwood and Y. R. Kim, "Microstructural investigation of asphalt concrete for performing multiscale experimental studies," International Journal of Pavement Engineering, vol. 14, no. 5, pp. 498-516, 2013.

[39] P. Cao, F. Jin, C. Zhou, D. Feng, and W. Song, "Steady-state dynamic method: an efficient and effective way to predict dynamic modulus of asphalt concrete," Construction and Building Materials, vol. 111, pp. 54-62, 2016.

[40] P. Cao, F. Jin, D. Feng, C. Zhou, and W. Hu, "Prediction on dynamic modulus of asphalt concrete with random aggregate modeling methods and virtual physics engine," Construction and Building Materials, vol. 125, pp. 987-997, 2016. 